\title{
Gender differences in the occurrence of nonfatal agricultural injuries among farmers in Fukuoka, Japan
}

\author{
Yoshito Momose ${ }^{1}$ and Takajiro Suenaga ${ }^{2}$ \\ ${ }^{1}$ Department of Preventive Medicine and Public Health, Faculty of Medicine, Fukuoka University, Japan \\ ${ }^{2}$ Department of Environmental Medicine, Faculty of Medicine, Kurume University, Japan
}

\begin{abstract}
Background: The lack of information regarding nonfatal agricultural injuries has been recognized as an obstacle for effective injury prevention. The aim of this study was to describe gender differences in the pattern of nonfatal agricultural injuries between the years 2008 and 2009.

Methods: Farmers' compensation injury claims were utilized to determine the mechanisms involved (machinery, non-machinery, and traffic), types of accident, sources of injury, kinds of injury, body parts affected place of injury, work being performed at the time of injury, and length of hospitalization. Agricultural injuries were identified using the International Classification of External Causes of Injury (ICECI). The Statistical Analysis System (SAS) software was used for all statistical analyses. Study variables were compared using the Mantel-Haenszel chi-square test.

Results: A total of 2,729 (1,921 males) farmers' compensation injury claims were analyzed. There were approximately 9 times as many nonfatal agricultural machinery injuries in males compared with females. The most common machinery injuries were cuts resulting from a rotary blade (31\%) for males and injuries caused by being struck by a machine (24\%) for females in the $65-89$ years of age group. The male:female ratio of non-machinery injuries averaged 2:1 (actual numbers of 1,293 and 676, respectively), but the percentage was higher for females $(83.7 \%)$ than males $(67.3 \%)$. For both males and females in the 65-89 years of age group, the main source of non-machinery injuries was slopes, the main type of accident was falling/slipping, the leading kind of injury was fracture, and the main work being performed was harvesting. Female farmers had a greater risk of prolonged hospitalization (more than 30 days) compared with males ( $\mathrm{p}<0.05)$.

Conclusions: Gender is an important factor to consider in the interpretation of nonfatal agricultural injuries. A greater number of males had machinery injuries than females; however, a higher per-
\end{abstract}

Received: 25 March 2015, Accepted: 29 May 2015

Correspondence: Yoshito Momose, Department of Preventive Medicine and Public Health, Faculty of Medicine, Fukuoka University, Nanakuma 7-45-1, Jonan-ku, Fukuoka 814-0180, Japan

E-mail: yoshito@cis.fukuoka-u.ac.jp centage of females had non-machinery injuries than males. Further research will be needed to understand the role of differential job tasks within agriculture in explaining the difference in risk.

Key words: agriculture, nonfatal, injury, farmer, gender

(J Rural Med 2015; 10(2): 57-64)

\section{Introduction}

According to the estimates for fatal injuries of the Ministry of Agriculture, Forestry and Fisheries in Japan, between the years 2000 and 2010, the number of agricultural fatalities per year (400) remained almost unchanged despite a dramatic decrease $(33 \%)$ in the number of farmers and an increase in their mean age from 61.1 to $65.8^{1-3)}$.

The farmers in Fukuoka face both an advancing age and declining population crisis, which mirrors the rest of the country. Between 2005 and 2010, their mean age increased from 61.9 to 64.5 , and the farming population declined from 95,023 to $68,091^{4)}$.

Historically, the work performed by males and females has been differentiated by job task. Although work activities may be substantially different when comparing males and females, females have traditionally been viewed as safer workers because the rate of work-related injuries is lower among females than among males. Few epidemiological studies on the occurrence of nonfatal agricultural injuries, however, have focused on information according to gen$\mathrm{der}^{5)}$. Female and male farmers would be expected to differ in their injury experiences because of their different tasks and roles within the agricultural setting. Both fatal and nonfatal injury rates are higher among farmers. Whereas fatality rate data for farmers are available, data on nonfatal agricultural injuries have been limited ${ }^{6}$. If the occurrence of nonfatal agricultural injuries differs by gender, then the risk of injury linked with those injuries would be expected to follow a different pattern for males and females. There is 
therefore an urgent need for more knowledge of gender differences in the occurrence of injury, mechanisms involved, and kinds of injury in farming in order to prevent nonfatal agricultural injuries.

This investigation involved analysis data from compensation claims for nonfatal agricultural injuries among farmers in Fukuoka for the years 2008 and 2009. The objective of this study was to describe the occurrence of nonfatal agricultural injuries among farmers who filed agricultural workers' compensation injury claims. A research partnership was established between the Fukuoka Association of Rural Medicine and National Mutual Insurance Federation of Agricultural Cooperatives in Fukuoka (JA Kyosai). JA Kyosai did not provide any financial support for this project.

\section{Materials and Methods}

\section{Data sources}

The JA Kyosai Medical Insurance policy covers hospitalization, including a certain number of days of medical treatment, in the event of illness or injury ${ }^{7}$. After obtaining approval from JA Kyosai, injury claims data for the period of January 2008 to December 2009 were copied by the investigators. Strict confidentiality of all claims data was enforced throughout this investigation. Claims data were electronically transmitted to the investigators, who were provided with password access. All personal identifiers were removed.

\section{Data analysis}

Gender differences in nonfatal agricultural injuries were examined by comparison of proportions using the MantelHaenszel chi-square test, with the level of statistical significance at $\mathrm{p}<0.05$, and by calculation of males:females ratios (defined as the number of events for males relative to females). Agricultural injuries were identified using International Classification of External Causes of Injury (ICECI) ${ }^{8}$. The database consisted of claimant information including farmer's age group (20-64 years of age and 65-89 years of age), gender (male and female), season (winter, spring, summer, and autumn), place (rice field, field for other crops, orchard, forest, and forecourt), work being performed at the time of injury (maintenance work, preparation/repairing, walking, harvesting, and carrying), part of body injured (head/face, hand/wrist, shoulder/chest, lumber region, upper extremity, lower extremity, and ankle/toe), type of machinery-related accident (fell/slipped, fell from machine, struck by machine, caught in machine, and cut by rotary blade), type of non-machinery-related accident (fell/slipped, fell from height, struck by/against objects, and cut by objects), source of machinery-related injury (tractor, combine, mowing machine, chain saw, and power sprayer), source of non-machinery-related injury (tree/tree branch, ladder, sickle, gutter, slope, and insects), kind of injury (fracture, cut wound, contusions, bruises, and sprain), mechanism involved in injury (machinery, non-machinery, and traffic), and length of hospitalization $(<30$ days and 30 days $\leq$ ). The definition of traffic was an accident involving motor vehicles being used for farm work (e.g., motor vehicle crashes that occurred during the transport of farm supplies). Study variables that did not fit the above categories were classified as "others." The Statistical Analysis System (SAS) software was used for all statistical analyses.

\section{Results}

A total of 2,729 farmers' compensation claims were analyzed. The frequency and percentage of nonfatal injuries are summarized in Table 1 according to gender, age group, and mechanisms involved in injuries. No significant gender difference was observed in any age group. The age group with the highest percentage of nonfatal injuries was 70 to 79 years of age for both males (43.8\%) and females (44.7\%). As shown in Table 1, statistically significant gender differences were found for the mechanisms involved in injuries ( $\mathrm{p}$ $<0.05$ ). The most common mechanisms involved in injuries were non-machinery for both males and females $(1,293$ and 676 , respectively), and the male:female ratio of non-machinery injuries averaged 2:1, with the percentage of injuries caused by non-machinery being higher for females $(83.7 \%)$ than males $(67.3 \%)$.

There were approximately 9 times as many machinery injuries in males compared with females (536 and 58, respectively), and a higher percentage of males (27.9\%) experienced these injuries than females (7.2\%).

As shown in Table 2, the highest ratio of males to females (11:1) occurred for those who had machinery injuries in the 20-64 years of age group. This pattern is in marked contrast to traffic injuries, which showed only slight variation in the male:female ratio by age group.

The frequencies and percentages of machinery injuries according to age group, type of accident, source of injury, kind of injury, and part of the body injured are shown in Table 3. A significant difference between genders was observed for type of accident in the 65-89 years of age group $(\mathrm{p}<0.05)$. The most frequent type of machinery accident among males was being cut by a rotary blade (31.4\%), and a higher percentage of males experienced this than females (12.2\%). Among females in the 65-89 years of age group, the most frequent type of machinery accident was being struck by a machine (24.4\%), followed by falling/slipping $(22.0 \%)$, and a higher percentage of females experienced 
Table 1 Characteristics of 2,729 nonfatal agricultural injuries in Fukuoka, 2008-2009

\begin{tabular}{|c|c|c|c|c|}
\hline \multirow{2}{*}{ Category } & \multicolumn{2}{|l|}{ Males } & \multicolumn{2}{|l|}{ Females } \\
\hline & No. of injuries & $(\%)$ & No. of injuries & $(\%)$ \\
\hline \multicolumn{5}{|l|}{ Age group } \\
\hline $20-29$ & 23 & $(1.2)$ & 2 & $(0.2)$ \\
\hline $30-39$ & 66 & $(3.4)$ & 9 & $(1.1)$ \\
\hline $40-49$ & 99 & $(5.1)$ & 25 & (3.1) \\
\hline $50-59$ & 195 & $(10.2)$ & 100 & (12.4) \\
\hline $60-69$ & 528 & $(27.5)$ & 259 & $(32.1)$ \\
\hline $70-79$ & 841 & $(43.8)$ & 361 & $(44.7)$ \\
\hline $80-89$ & 169 & $(8.8)$ & 52 & $(6.4)$ \\
\hline All ages & 1921 & $(100)$ & 808 & $(100)$ \\
\hline \multicolumn{5}{|c|}{ Mechanism involved in injury } \\
\hline Machinery & 536 & $(27.9)$ & 58 & $(7.2)$ \\
\hline Non-machinery & 1293 & $(67.3)$ & 676 & $(83.7)$ \\
\hline Traffic & 81 & $(4.2)$ & 69 & $(8.5)$ \\
\hline Unknown & 11 & $(0.6)$ & 5 & $(0.6)$ \\
\hline Total & $1921^{\mathrm{a}}$ & (100) & $808^{\mathrm{b}}$ & (100) \\
\hline
\end{tabular}

Table 2 Nonfatal agricultural injuries by mechanism involved in injury, gender, and age group in Fukuoka

\begin{tabular}{|c|c|c|c|c|c|c|c|c|c|}
\hline \multirow[b]{2}{*}{ Age group } & \multicolumn{3}{|c|}{ Machinery } & \multicolumn{3}{|c|}{ Non-machinery } & \multicolumn{3}{|c|}{ Traffic } \\
\hline & $\begin{array}{l}\text { Males } \\
\mathrm{n}(\%)\end{array}$ & $\begin{array}{c}\text { Females } \\
\mathrm{n}(\%)\end{array}$ & $\begin{array}{l}\mathrm{M}: \mathrm{F} \\
\text { ratio }\end{array}$ & $\begin{array}{c}\text { Males } \\
\mathrm{n}(\%)\end{array}$ & $\begin{array}{c}\text { Females } \\
\mathrm{n}(\%)\end{array}$ & $\begin{array}{l}\mathrm{M}: \mathrm{F} \\
\text { ratio }\end{array}$ & $\begin{array}{c}\text { Males } \\
\mathrm{n}(\%)\end{array}$ & $\begin{array}{c}\text { Females } \\
\mathrm{n}(\%)\end{array}$ & $\begin{array}{l}\mathrm{M}: \mathrm{F} \\
\text { ratio }\end{array}$ \\
\hline $20-64$ & $198(36.9)$ & $17(29.3)$ & $11: 1$ & $383(29.6)$ & $189(28.0)$ & $2: 1$ & $17(21.0)$ & 17 (24.6) & $1: 1$ \\
\hline $65-89$ & $338(63.1)$ & $41(70.7)$ & $8: 1$ & $910(70.4)$ & $487(72.0)$ & $2: 1$ & $64(79.0)$ & $52(75.4)$ & $1: 1$ \\
\hline Total & $536(100)$ & $58(100)$ & $9: 1$ & $1293(100)$ & $676(100)$ & $2: 1$ & $81(100)$ & $69(100)$ & $1: 1$ \\
\hline
\end{tabular}

M:F ratio is defined as the number of events for males relative to females.

this than males $(10.4 \%)$. Although no significant gender differences in source of injury, kind of machinery injuries, and part of the body injured were observed in the 65-89 years of age group, mowing machines were the leading source of machinery injuries among both males $(25.2 \%)$ and females (24.4\%). The main kind of machinery injury in the $65-89$ years of age group was contusions among males (24.3\%), but it was bone fracture among females $(34.2 \%)$. The most frequent part of the body injured by machinery in the 65-89 years of age group was the hand/wrist among males (35.8\%), but it was the lower extremity among females (29.3\%). No significant gender differences in type of injury, source of injury, kind of injury, and body part injured with respect to machinery injuries were observed in the 20-64 years of age group.

The frequencies and percentages of machinery injuries according to age group, place, work being performed at the time of injury, and length of hospitalization are shown in Table 4. A significant difference between genders was observed in the work being performed at the time of machinery injuries in the 20-64 years of age group $(p<0.05)$. The most frequent work being performed at the time of machinery injuries among males was harvesting $(44.4 \%)$ followed by maintenance work $(20.7 \%)$, and higher percentages of males performed this work than females $(29.4 \%$ and $5.9 \%$, respectively). In the 65-89 years of age group, prolonged hospitalization (more than 30 days) as a result of machinery injuries was observed in a significantly higher percentage of injured females (24.4\%) than males $(9.5 \%)$.

The frequencies and percentages of non-machinery injuries according to type of accident, source of injury, kind of injury, and part of the body injured are shown in Table 5 . The source of non-machinery injuries was found to be statistically significant in both age groups (20-64 and 65-89 years of age groups: $p<0.05$ ). In the $20-64$ years of age group, the most frequent source of non-machinery injuries among males was the sickle (15.4\%), but it was slopes (17.5\%) among females. Ladders were a source of non-machinery injury in a higher percentage of males (11.8\%) than females $(8.5 \%)$. In the $65-89$ years of age group, the main source of non-machinery injuries was slopes among both males $(17.8 \%)$ and females $(22.0 \%)$. The next highest sources of 
Table 3 Nonfatal agricultural injuries caused by machinery according to age group and gender in Fukuoka

\begin{tabular}{|c|c|c|c|c|c|c|c|c|}
\hline \multirow{3}{*}{ Machinery } & \multicolumn{4}{|c|}{ Age $20-64$} & \multicolumn{4}{|c|}{ Age $65-89$} \\
\hline & \multicolumn{2}{|c|}{ Males } & \multicolumn{2}{|c|}{ Females } & \multicolumn{2}{|c|}{ Males } & \multicolumn{2}{|c|}{ Females } \\
\hline & $\mathrm{n}$ & $(\%)$ & $\mathrm{n}$ & $(\%)$ & $\mathrm{n}$ & $(\%)$ & $\mathrm{n}$ & $(\%)$ \\
\hline \multicolumn{9}{|l|}{ Type of accident } \\
\hline Fall/slip & 12 & $(6.1)$ & 1 & $(5.9)$ & 35 & $(10.4)$ & 9 & $(22.0)$ \\
\hline Fall from the machine & 15 & (7.6) & 1 & $(5.9)$ & 23 & $(6.8)$ & 3 & $(7.3)$ \\
\hline Struck by machine & 51 & $(25.8)$ & 7 & $(41.2)$ & 100 & $(29.6)$ & 10 & $(24.4)$ \\
\hline Caught in machine & 30 & $(15.2)$ & 3 & $(17.7)$ & 42 & $(12.4)$ & 3 & $(7.3)$ \\
\hline Cut by a rotary blade & 61 & $(30.8)$ & 2 & $(11.8)$ & 106 & $(31.4)$ & 5 & $(12.2)$ \\
\hline Others & 29 & $(14.7)$ & 3 & $(17.7)$ & 32 & $(9.5)$ & 11 & $(26.8)$ \\
\hline Total & 198 & $(100)$ & 17 & $(100)$ & $338^{\mathrm{a}}$ & $(100)$ & $41^{\mathrm{b}}$ & $(100)$ \\
\hline \multicolumn{9}{|l|}{ Source of injury } \\
\hline Tractor & 37 & $(18.7)$ & 1 & (5.9) & 75 & $(22.2)$ & 3 & (7.3) \\
\hline Combine & 17 & $(8.6)$ & 4 & $(23.5)$ & 25 & $(7.4)$ & 6 & $(14.6)$ \\
\hline Mowing machine & 50 & $(25.3)$ & 3 & $(17.7)$ & 85 & $(25.2)$ & 10 & $(24.4)$ \\
\hline Chainsaw & 22 & $(11.1)$ & 0 & $(0.0)$ & 36 & $(10.7)$ & 0 & $(0.0)$ \\
\hline Power sprayer & 8 & $(4.0)$ & 0 & $(0.0)$ & 7 & $(2.1)$ & 9 & $(22.0)$ \\
\hline Others & 64 & $(32.3)$ & 9 & $(52.9)$ & 110 & $(32.5)$ & 13 & $(31.7)$ \\
\hline Total & 198 & $(100)$ & 17 & $(100)$ & 338 & $(100)$ & 41 & (100) \\
\hline \multicolumn{9}{|l|}{ Kind of injury } \\
\hline Fracture & 39 & (19.7) & 2 & $(11.8)$ & 78 & $(23.1)$ & 14 & $(34.2)$ \\
\hline Cut wound & 41 & $(20.7)$ & 3 & (17.7) & 68 & $(20.1)$ & 2 & $(4.9)$ \\
\hline Contusions & 41 & $(20.7)$ & 3 & $(17.7)$ & 82 & $(24.3)$ & 8 & $(19.5)$ \\
\hline Bruises & 20 & $(10.1)$ & 2 & $(11.8)$ & 35 & $(10.4)$ & 7 & $(17.1)$ \\
\hline Sprain & 10 & $(5.1)$ & 0 & $(0.0)$ & 10 & $(3.0)$ & 2 & $(4.9)$ \\
\hline Others & 47 & $(23.7)$ & 7 & $(41.2)$ & 65 & $(19.2)$ & 8 & $(19.5)$ \\
\hline Total & 198 & $(100)$ & 17 & $(100)$ & 338 & $(100)$ & 41 & $(100)$ \\
\hline \multicolumn{9}{|l|}{ Part of body injured } \\
\hline Head/face & 26 & $(13.1)$ & 3 & $(17.7)$ & 28 & $(8.3)$ & 7 & $(17.1)$ \\
\hline Hand/wrist & 69 & $(34.9)$ & 8 & $(47.1)$ & 121 & $(35.8)$ & 6 & $(14.6)$ \\
\hline Shoulder/chest & 7 & $(3.5)$ & 1 & $(5.9)$ & 23 & $(6.8)$ & 3 & (7.3) \\
\hline Lumbar region & 4 & (2.0) & 1 & (5.9) & 16 & $(4.7)$ & 4 & (9.8) \\
\hline Upper extremity & 7 & (3.5) & 0 & $(0.0)$ & 29 & $(8.6)$ & 4 & (9.8) \\
\hline Lower extremity & 49 & $(24.8)$ & 1 & (5.9) & 75 & $(22.2)$ & 12 & $(29.3)$ \\
\hline Ankle/toe & 26 & (13.1) & 1 & (5.9) & 36 & $(10.7)$ & 4 & $(9.8)$ \\
\hline Others & 10 & (5.1) & 2 & $(11.8)$ & 10 & $(3.0)$ & 1 & $(2.4)$ \\
\hline Total & 198 & $(100)$ & 17 & $(100)$ & 338 & $(100)$ & 41 & (100) \\
\hline
\end{tabular}

${ }^{\mathrm{a}-\mathrm{b}} \mathrm{p}<0.05$.

non-machinery injuries in percentage in the 65-89 years of age group were trees/tree branches and ladders among males $(15.7 \%, 14.0 \%$, respectively), and the percentages were higher for males than females $(6.2 \%, 7.8 \%$, respectively). Bone fracture was the leading kind of non-machinery injury among both males $(28.1 \%)$ and females $(44.8 \%)$ in the 65-89 years of age group, and a higher percentage of females experienced this kind of injury than males $(p<0.05)$.

The frequencies and percentages of non-machinery injuries according to age group, place, work being performed at the time of injury, and length of hospitalization are shown in Table 6. Significant differences between genders were observed in place, work being performed, and length of hospitalization in the 65-89 years of age group $(\mathrm{p}<0.05)$. The most frequent place of non-machinery injury was in the forecourt (18.2\%) among males, and a higher percentage of males experienced non-machinery injuries in the forecourt than females (12.3\%). Among females, the most frequent place of non-machinery injury was the fields for other crops (32.2\%), and a higher percentage of females experienced non-machinery injuries in the fields for other crops than males (14.4\%). The main work being performed at the time of non-machinery injury was harvesting among both males (50.8\%) and females (38.0\%). Prolonged hospitaliza- 
Table 4 Nonfatal agricultural injuries caused by machinery according to age group and gender in Fukuoka

\begin{tabular}{|c|c|c|c|c|c|c|c|c|}
\hline \multirow{3}{*}{ Machinery } & \multicolumn{4}{|c|}{ Age 20-64 } & \multicolumn{4}{|c|}{ Age $65-89$} \\
\hline & \multicolumn{2}{|c|}{ Males } & \multicolumn{2}{|c|}{ Females } & \multicolumn{2}{|c|}{ Males } & \multicolumn{2}{|c|}{ Females } \\
\hline & $\mathrm{n}$ & $(\%)$ & $\mathrm{n}$ & $(\%)$ & $\mathrm{n}$ & $(\%)$ & $\mathrm{n}$ & $(\%)$ \\
\hline \multicolumn{9}{|l|}{ Place of injury } \\
\hline Rice field & 43 & $(21.7)$ & 4 & $(23.5)$ & 53 & $(15.7)$ & 9 & $(22.0)$ \\
\hline Field for other crops & 29 & $(14.7)$ & 6 & $(35.3)$ & 61 & $(18.1)$ & 10 & $(24.4)$ \\
\hline Orchard & 14 & $(7.1)$ & 0 & $(0.0)$ & 26 & $(7.7)$ & 2 & $(4.9)$ \\
\hline Forest & 19 & (9.6) & 0 & $(0.0)$ & 38 & $(11.2)$ & 0 & $(0.0)$ \\
\hline Forecourt & 20 & $(10.1)$ & 2 & $(11.8)$ & 38 & $(11.2)$ & 6 & $(14.6)$ \\
\hline Others & 73 & $(36.9)$ & 5 & $(29.4)$ & 122 & $(36.1)$ & 14 & $(34.2)$ \\
\hline Total & 198 & $(100)$ & 17 & $(100)$ & 338 & $(100)$ & 41 & $(100)$ \\
\hline \multicolumn{9}{|c|}{ Work being performed at time of injury } \\
\hline Maintenance work & 41 & $(20.7)$ & 1 & $(5.9)$ & 60 & $(17.8)$ & 3 & $(7.3)$ \\
\hline Preparation/repairs & 7 & (3.5) & 0 & $(0.0)$ & 18 & $(5.3)$ & 6 & $(14.6)$ \\
\hline Walking & 14 & $(7.1)$ & 1 & $(5.9)$ & 20 & $(5.9)$ & 1 & $(2.4)$ \\
\hline Harvesting & 88 & $(44.4)$ & 5 & $(29.4)$ & 156 & $(46.2)$ & 20 & $(48.8)$ \\
\hline Carrying & 19 & $(9.6)$ & 5 & $(29.4)$ & 27 & $(8.0)$ & 5 & $(12.2)$ \\
\hline Others & 29 & $(14.7)$ & 5 & $(29.4)$ & 57 & $(16.9)$ & 6 & $(14.6)$ \\
\hline Total & $198^{\mathrm{a}}$ & $(100)$ & $17^{\mathrm{b}}$ & $(100)$ & 338 & $(100)$ & 41 & $(100)$ \\
\hline \multicolumn{9}{|l|}{ Length of hospitalization } \\
\hline$<30$ days & 180 & $(90.9)$ & 15 & $(88.2)$ & 306 & $(90.5)$ & 31 & $(75.6)$ \\
\hline 30 days $\leq$ & 18 & $(9.1)$ & 2 & $(11.8)$ & 32 & $(9.5)$ & 10 & $(24.4)$ \\
\hline Total & 198 & $(100)$ & 17 & $(100)$ & $338^{\mathrm{a}}$ & $(100)$ & $41^{\mathrm{b}}$ & $(100)$ \\
\hline
\end{tabular}

${ }^{\mathrm{a}-\mathrm{b}} \mathrm{p}<0.05$.

tion (more than 30 days) as a result of non-machinery injury occurred in a significantly higher percentage of injured females $(16.6 \%)$ than males $(12.2 \%)$.

The data regarding traffic as a mechanism involved in injury was insufficient for analysis, so traffic was excluded from the results. No significant difference in the season of injury occurrence was observed by gender, so the data for this were excluded from the tables in this study.

\section{Discussion}

This study provided a unique opportunity to investigate farmers' compensation claims in Fukuoka. A nationwide investigation, which also used data from farmers' compensation claims, was reported in $2003^{9}$. The results showed that farmers 60 years of age or older who were injured by agricultural machinery accidents accounted for more than $50 \%$ of the total. Furthermore, the main source of non-machinery accidents was the sickle, stepladders, and ladders, which accounted for $61 \%$ of the agricultural equipment.

Our investigation is the first to characterize nonfatal agricultural injuries using farmers' compensation claims data and covering the period of January 2008 to December 2009. Differences between males and females were apparent in the patterns of nonfatal agricultural injury. Nonfatal inju- ries occurred predominantly in males. We found the ratio of males to females to be 9:1 for machinery injuries. The extent of the difference in the numbers of agricultural injuries between the genders has been corroborated in other surveys ${ }^{5,10)}$. The disparity between the genders in injuries involving farm machinery most likely reflects differences in exposure. We found that the leading types of machinery accidents were being cut by a rotary blade for males and being struck by a machine for females in the 65-89 years of age group. The high risk of machinery accidents, particularly those involving a tractor, combine, or mowing machine, has been well documented ${ }^{11)}$. This indicates that the frequencies of nonfatal machinery injuries with these kinds of machinery can be reduced by farmers ensuring that they operate the machinery safely. In the 20-64 years of age group, the main kinds of work being performed at the time of machinery injuries were harvesting and maintenance work among males, and higher percentages of males performed these kinds of work than females. Further detailed analysis is necessary about agricultural machinery injuries during harvesting and maintenance work.

The source of non-machinery injuries was gender dependent in both age groups. A greater percentage of nonmachinery injuries were due to slopes for males in the elderly group and for all females. Working on slopes is often 
Table 5 Nonfatal agricultural injuries caused by non-machinery according to age group and gender in Fukuoka

\begin{tabular}{|c|c|c|c|c|c|c|c|c|}
\hline \multirow{3}{*}{ Non-machinery } & \multicolumn{4}{|c|}{ Age $20-64$} & \multicolumn{4}{|c|}{ Age $65-89$} \\
\hline & \multicolumn{2}{|c|}{ Males } & \multicolumn{2}{|c|}{ Females } & \multicolumn{2}{|c|}{ Males } & \multicolumn{2}{|c|}{ Females } \\
\hline & $\mathrm{n}$ & $(\%)$ & $\mathrm{n}$ & $(\%)$ & $\mathrm{n}$ & $(\%)$ & $\mathrm{n}$ & $(\%)$ \\
\hline \multicolumn{9}{|l|}{ Type of accident } \\
\hline Fall/slip & 67 & $(17.5)$ & 66 & $(34.9)$ & 263 & $(28.9)$ & 217 & $(44.6)$ \\
\hline Fall from height & 77 & $(20.1)$ & 29 & $(15.3)$ & 223 & $(24.5)$ & 98 & $(20.1)$ \\
\hline Struck by/against objects & 56 & $(14.6)$ & 19 & $(10.1)$ & 138 & $(15.2)$ & 34 & $(7.0)$ \\
\hline Cut by objects & 54 & $(14.1)$ & 19 & $(10.1)$ & 96 & $(10.6)$ & 43 & $(8.8)$ \\
\hline Others & 129 & $(33.7)$ & 56 & $(29.6)$ & 190 & $(20.9)$ & 95 & $(19.5)$ \\
\hline Total & 383 & $(100)$ & 189 & $(100)$ & 910 & $(100)$ & 487 & $(100)$ \\
\hline \multicolumn{9}{|l|}{ Source of injury } \\
\hline Tree/tree branch & 54 & $(14.1)$ & 19 & $(10.1)$ & 143 & $(15.7)$ & 30 & $(6.2)$ \\
\hline Ladder & 45 & (11.8) & 16 & $(8.5)$ & 127 & $(14.0)$ & 38 & (7.8) \\
\hline Sickle & 59 & (15.4) & 20 & $(10.6)$ & 83 & $(9.1)$ & 42 & (8.6) \\
\hline Gutter & 15 & (3.9) & 4 & $(2.1)$ & 47 & $(5.2)$ & 24 & (4.9) \\
\hline Slope & 42 & $(11.0)$ & 33 & $(17.5)$ & 162 & $(17.8)$ & 107 & $(22.0)$ \\
\hline Insects & 31 & $(8.1)$ & 17 & $(9.0)$ & 29 & $(3.2)$ & 15 & (3.1) \\
\hline Others & 137 & $(35.8)$ & 80 & $(42.3)$ & 319 & $(35.1)$ & 231 & $(47.4)$ \\
\hline Total & $383^{\mathrm{a}}$ & $(100)$ & $189^{\mathrm{b}}$ & $(100)$ & $910^{\mathrm{a}}$ & $(100)$ & $487^{\mathrm{b}}$ & $(100)$ \\
\hline \multicolumn{9}{|l|}{ Kind of injury } \\
\hline Fracture & 90 & $(23.5)$ & 62 & $(32.8)$ & 256 & $(28.1)$ & 218 & $(44.8)$ \\
\hline Cut wound & 65 & $(17.0)$ & 21 & (11.1) & 115 & (12.6) & 40 & $(8.2)$ \\
\hline Contusions & 42 & $(11.0)$ & 22 & (11.6) & 145 & $(15.9)$ & 47 & (9.7) \\
\hline Bruises & 45 & $(11.8)$ & 23 & $(12.2)$ & 132 & $(14.5)$ & 69 & (14.2) \\
\hline Sprain & 31 & $(8.1)$ & 15 & (7.9) & 53 & $(5.8)$ & 32 & (6.6) \\
\hline Others & 110 & $(28.7)$ & 46 & $(24.3)$ & 209 & $(23.0)$ & 81 & $(16.6)$ \\
\hline Total & 383 & $(100)$ & 189 & $(100)$ & $910^{\mathrm{a}}$ & $(100)$ & $487^{\mathrm{b}}$ & $(100)$ \\
\hline \multicolumn{9}{|l|}{ Part of body injured } \\
\hline Head/face & 36 & (9.4) & 21 & (11.1) & 92 & $(10.1)$ & 24 & (4.9) \\
\hline Hand/wrist & 97 & $(25.3)$ & 50 & $(26.5)$ & 196 & $(21.5)$ & 99 & (20.3) \\
\hline Shoulder/chest & 40 & $(10.4)$ & 16 & $(8.5)$ & 137 & $(15.1)$ & 50 & $(10.3)$ \\
\hline Lumbar region & 30 & $(7.8)$ & 8 & (4.2) & 97 & $(10.7)$ & 69 & $(14.2)$ \\
\hline Upper extremity & 38 & (9.9) & 23 & $(12.2)$ & 82 & $(9.0)$ & 62 & $(12.7)$ \\
\hline Lower extremity & 73 & $(19.1)$ & 40 & $(21.2)$ & 157 & $(17.3)$ & 119 & $(24.4)$ \\
\hline Ankle/toe & 43 & (11.2) & 23 & $(12.2)$ & 95 & (10.4) & 42 & $(8.6)$ \\
\hline Others & 26 & $(6.8)$ & 8 & $(4.2)$ & 54 & $(5.9)$ & 22 & $(4.5)$ \\
\hline Total & 383 & $(100)$ & 189 & $(100)$ & 910 & $(100)$ & 487 & (100) \\
\hline
\end{tabular}

${ }^{\mathrm{a}-\mathrm{b}} \mathrm{p}<0.05$.

a necessity while working along the banks of a field or farm. With regard to the type of accident, falls/slipping and falls from height accounted for a higher percentage among males and females than any other type of accident. Fracture was the most frequent kind of non-machinery injuries among both males and females in the 65-89 years of age group. The results of the present study, however, are inconsistent with previous agriculture studies found that the leading kinds of nonfatal injuries are sprains or cuts ${ }^{12,13}$. They are also inconsistent with the previous report that the most frequently injured body parts are the shoulder and lumbar region ${ }^{13)}$. Often, farmers fall from slopes, banks, ladders, or wet areas at the farm. Elderly farmers are particularly at risk ${ }^{14)}$. Risk factors for elderly farmers include visual impairment and gait and balance disturbances. In addition, the leading kind of injury was fractures, and the percentage among females was higher than that of males. Degenerative changes with aging, such as osteoporosis, may be important factors. The high risk of injury from farming activities among elderly males has been identified in previous studies and attributed to the onset of age-related physiological changes, such as slowing of reaction time ${ }^{15}$. The gender disparity in nonfatal injuries may also reflect less participation and hence less exposure among females over age 65. Counseling regard- 
Table 6 Nonfatal agricultural injuries caused by non-machinery according to age group, and gender in Fukuoka

\begin{tabular}{|c|c|c|c|c|c|c|c|c|}
\hline \multirow{3}{*}{ Non-machinery } & \multicolumn{4}{|c|}{ Age $20-64$} & \multicolumn{4}{|c|}{ Age $65-89$} \\
\hline & \multicolumn{2}{|c|}{ Males } & \multicolumn{2}{|c|}{ Females } & \multicolumn{2}{|c|}{ Males } & \multicolumn{2}{|c|}{ Females } \\
\hline & $\mathrm{n}$ & $(\%)$ & $\mathrm{n}$ & $(\%)$ & $\mathrm{n}$ & $(\%)$ & $\mathrm{n}$ & $(\%)$ \\
\hline \multicolumn{9}{|l|}{ Place of injury } \\
\hline Rice field & 38 & (9.9) & 15 & (7.9) & 111 & $(12.2)$ & 49 & $(10.1)$ \\
\hline Field for other crops & 51 & (13.3) & 45 & $(23.8)$ & 131 & $(14.4)$ & 157 & $(32.2)$ \\
\hline Orchard & 30 & $(7.8)$ & 28 & $(14.8)$ & 79 & $(8.7)$ & 61 & $(12.5)$ \\
\hline Forest & 45 & $(11.8)$ & 10 & $(5.3)$ & 137 & $(15.1)$ & 27 & $(5.5)$ \\
\hline Forecourt & 59 & (15.4) & 11 & $(5.8)$ & 166 & $(18.2)$ & 60 & (12.3) \\
\hline Others & 160 & $(41.8)$ & 80 & $(42.3)$ & 286 & (31.4) & 133 & $(27.4)$ \\
\hline Total & 383 & $(100)$ & 189 & $(100)$ & $910^{\mathrm{a}}$ & $(100)$ & $487^{\mathrm{b}}$ & $(100)$ \\
\hline \multicolumn{9}{|c|}{ Work being performed at time of injury } \\
\hline Maintenance work & 44 & $(11.5)$ & 17 & $(9.0)$ & 82 & $(9.0)$ & 18 & $(3.7)$ \\
\hline Preparation/repairs & 38 & $(9.9)$ & 25 & $(13.2)$ & 92 & $(10.1)$ & 61 & $(12.5)$ \\
\hline Walking & 16 & $(4.2)$ & 11 & $(5.8)$ & 60 & $(6.7)$ & 41 & $(8.4)$ \\
\hline Harvesting & 184 & $(48.0)$ & 58 & $(30.7)$ & 462 & $(50.8)$ & 185 & $(38.0)$ \\
\hline Carrying & 20 & $(5.2)$ & 26 & $(13.8)$ & 70 & $(7.7)$ & 72 & $(14.8)$ \\
\hline Others & 81 & $(21.2)$ & 52 & $(27.5)$ & 144 & $(15.8)$ & 110 & $(22.6)$ \\
\hline Total & 383 & $(100)$ & 189 & $(100)$ & $910^{\mathrm{a}}$ & $(100)$ & $487^{\mathrm{b}}$ & $(100)$ \\
\hline \multicolumn{9}{|c|}{ Length of hospitalization } \\
\hline$<30$ days & 357 & $(93.2)$ & 169 & $(89.4)$ & 799 & $(87.8)$ & 406 & $(83.4)$ \\
\hline 30 days $\leq$ & 26 & $(6.8)$ & 20 & $(10.6)$ & 111 & $(12.2)$ & 81 & (16.6) \\
\hline Total & 383 & $(100)$ & 189 & $(100)$ & $910^{\mathrm{a}}$ & $(100)$ & $487^{\mathrm{b}}$ & $(100)$ \\
\hline
\end{tabular}

${ }^{\mathrm{a}-\mathrm{b}} \mathrm{p}<0.05$.

ing the greater likelihood of falls by elderly farmers seems to be warranted. A general safety program oriented toward ladder safety and proper footwear should be encouraged in this group.

\section{Study limitations}

The use of farm workers' compensation claims data to analyze nonfatal agricultural injuries is an inherent limitation of this study. Furthermore, use of the ICECI coding for analysis of agriculture-related injuries made it difficult to correlate with a recognized Japanese classification of causes of agricultural injury. Despite these limitations, the authors believe that analysis of agriculture-related sectors in Fukuo$\mathrm{ka}$ is vital to future injury prevention research efforts.

A second limitation in the use of farm workers' compensation claims data for injury surveillance is the dependence on injury reporting ${ }^{16}$. Workers' compensation data could potentially underreport the true number of injuries in agriculture because both the worker and physician must recognize that a condition is work related. Many farm workers live on the farms that they operate, and differentiation between an agricultural and nonagricultural injury may be difficult. Also, these data were drawn from a sample of farmers in the southern part of Japan. Therefore, findings may not be generalizable to farmers in different regions of
Japan, who may experience different injury risks because of differences in crops, terrain, weather conditions, etc.

This study utilized injury claims data from 2008 to 2009. An investigation that included a longer time period would be more representative of the specific occupational sector and make it possible to reveal injury trends.

Despite these limitations, this study is the first of its kind to utilize workers' compensation injury claims data to investigate specific agriculture-related injuries in Fukuoka and to provide information regarding the characteristics of nonfatal injuries that can be used to develop effective injury prevention strategies.

\section{Conclusion}

Gender is an important factor to consider in the interpretation of nonfatal agricultural injuries. A greater number of males had machinery injuries than females; however, a higher percentage of females had non-machinery injuries than males. Further research will be needed to understand the role of differential job tasks within agriculture in explaining the difference in risk. 


\section{Acknowledgments}

The authors express their appreciation to JA Kyosai, the National Mutual Insurance Federation of Agricultural Cooperatives in Fukuoka, for providing the claims data used in this investigation, as well as for their ongoing collaborative support and emphasis on occupational injury prevention.

\section{References}

1. The Ministry of Agriculture, Forestry and Fisheries in Japan. FY2010; Annual report on food, agriculture, and rural area in Japan, Chapter 2: Toward sustainable development of agriculture, 3 . Trends of farms and farmers.

2. Sasaki S, Usuda M, Hirosawa M, et al. Research on prevention of agricultural accidents. Nihon Noson Igakkai Zasshi 2005; 53: 796-804 (in Japanese).

3. Mikurube M, Hyon I, Ando M, et al. Study on agricultural accidents. Nihon Noson Igakkai Zasshi 2008; 56: 770-782 (in Japanese).

4. The Ministry of Agriculture, Forestry and Fisheries in Fukuoka. FY2010; Statistics of Agriculture in Fukuoka (in Japanese).

5. Dimich-Ward H, Guernsey JR, Pickett W, et al. Gender differences in the occurrence of farm related injuries. Occup Environ Med 2004; 61: 52-56. [Medline]

6. Brison RJ, Pickett CW. Non-fatal farm injuries on 117 eastern Ontario beef and dairy farms: a one-year study. Am J Ind Med 1992; 21: 623-636. [Medline] [CrossRef]

7. The National Mutual Insurance Federation of Agricultural Cooperatives. Annual report 2014. Zenkyoren's business.
8. Scott D, Harrison J, Purdie D, et al. The properties of the International Classification of the External Cause of Injury when used as an instrument for injury prevention research. Inj Prev 2006; 12: 253-257. [Medline] [CrossRef]

9. Shimizu S, Sasaki S, Suenaga T, et al. Study of the agricultural accidents and protective measures. Kyosai Examiner Tsushin. National Mutual Insurance Federation of Agricultural Cooperatives. 2003; 13: 1-14 (in Japanese).

10. Gunderson P, Gerberich S, Gibson R, et al. Injury surveillance in agriculture. Am J Ind Med 1990; 18: 169-178. [Medline] [CrossRef]

11. Tatsumi M. The actual circumstances and future counterbalance of the agricultural accidents. Jpn J Assoc Health Safety Consulting 2013; No.107: 50-55 (in Japanese).

12. Browning SR, Truszczynska H, Reed D, et al. Agricultural injuries among older Kentucky farmers: the farm family health and hazard surveillance study. Am J Ind Med 1998; 33: 341353. [Medline] [CrossRef]

13. Sprince NL, Zwerling C, Lynch CF, et al. Risk factors for falls among Iowa farmers: a case-control study nested in the Agricultural Health Study. Am J Ind Med 2003; 44: 265-272. [Medline] [CrossRef]

14. Hsiao H. Fall prevention research and practice: a total worker safety approach. Ind Health 2014; 52: 381-392. [Medline] [CrossRef]

15. Voaklander DC, Hartling L, Pickett W, et al. Work-related mortality among older farmers in Canada. Can Fam Physician 1999; 45: 2903-2910. [Medline]

16. Douphrate DI, Rosecrance JC, Wahl G. Workers' compensation experience of Colorado agriculture workers, 2000-2004. Am J Ind Med 2006; 49: 900-910. [Medline] [CrossRef] 